\title{
A unidade teoria-prática e o papel da supervisão de estágio nessa construção
}

\author{
Rivânia Lúcia Moura de Assis \\ Universidade do Estado do Rio Grande do Norte (UERN)
}

\author{
Iana Vasconcelos Moreira Rosado \\ Universidade do Estado do Rio Grande do Norte (UERN)
}

\begin{abstract}
A unidade teoria-prática e o papel da supervisão de estágio nessa construção
Resumo: Este artigo apresenta reflexões sobre a unidade teoria-prática no âmbito do Serviço Social, apontando os principais dilemas que a perpassam, tendo como base o estágio supervisionado. Busca particularizar o estágio como o momento potencializador dos grandes questionamentos sobre o sentido atribuído à relação entre a teoria e a prática e as formas como se expressa essa relação no cotidiano profissional. Discorre sobre o papel fundamental que a supervisão de estágio assume como processo didático-pedagógico, capaz de articular as dimensões teórico-metodológica, ético-política e técnico-operativa, as quais compõem a formação e o exercício profissional.
\end{abstract}

Palavras-chave: Unidade teoria-prática. Serviço Social. Supervisão de estágio. Estágio supervisionado. Formação profissional.

The Unity of Theory and Practice and the Role of Supervising Internships in this Construction

Abstract: This article presents reflections on the unity of theory and practice in the realm of Social Work, pointing to the main dilemmas related to the issue, based on the supervised internship. It seeks to particularize internships as moments that give potential to strong questionings about the meaning attributed to the relationship between theory and practice and to the ways that this relationship is expressed in the daily work of the professional. It looks at the fundamental role that the supervision of internships has in the didacticpedagogical process, which is capable of articulating the theoretical-methodological, ethical-political and technical-operative dimensions that compose education and professional activity.

Keywords: Unity of theory and practice. Social Work. Internship supervision. Supervised internship. Professional education. 


\section{Apresentação}

Este artigo é resultado de pesquisas, estudos teóricos e documentais e das observações e reflexões concretizadas a partir das nossas experiências, tanto na coordenação de estágio como também na supervisão acadêmica do curso de Serviço Social da Universidade do Estado do Rio Grande do Norte (UERN). Durante esse período institucionalizamos o fórum de supervisoras de estágio, o que possibilitou uma melhor compreensão das dificuldades e dos desafios enfrentados no âmbito da supervisão e, ainda, colher sugestões para potencializar o estágio como momento relevante de reflexões coletivas e de aprendizado no âmbito da formação profissional.

A motivação para escrever esse artigo surgiu de duas preocupações. A primeira, relaciona-se à observação de que, no momento do estágio, torna-se mais clara a dificuldade dos ${ }^{1}$ estudantes para perceber, em meio à vivência no espaço institucional, a relação teoria-prática, de onde surge a afirmação recorrente de que "na prática é tudo diferente do que estudamos na academia". O segundo fato a nos preocupar é a expectativa comumente gerada nos discentes pela disciplina de estágio. Espera-se que mediante a supervisão seja possível o ensino da prática como um movimento mecânico ou como uma relação específica somente do estágio, sem considerar a formação profissional em sua totalidade.

As discussões que apresentamos advêm dos nossos estudos e pesquisas, individuais e coletivos, das visitas feitas aos campos de estágio, das reuniões do fórum de supervisoras, bem como das experiências vivenciadas nas aulas das disciplinas de estágio supervisionado, realizadas com os grupos de estagiários ou por área ${ }^{2}$, na qual participam estudantes e supervisores acadêmicos e de campo.

O texto, fundamentado nesses estudos, inicia discutindo a relação entre teoria e prática no âmbito do Serviço Social para em seguida discorrer sobre o papel da supervisão acadêmica. Por fim, elenca alguns avanços e desafios da supervisão após as regulamentações mais recentes - Resolução de Estágio n. 533 (CFESS, 2008) e Política Nacional de Estágio (PNE) - inseridas no nosso contexto profissional, que é o ponto de partida dessas pesquisas.

\section{A relação entre teoria e prática no Serviço Social}

Pensar a relação entre teoria e prática no Serviço Social remete-nos a discutir sua compreensão no âmbito do exercício e da formação profissional. Alguns equívocos sobre essa relação entendem a prática como exclusiva da intervenção profissional e a teoria como algo específico do âmbito acadêmico. Para desfazer esse equívoco, reafirmamos, a necessidade de pensar teoria e prática como unidade, embora com características diferenciadas, mas que só se realizam em interação mútua, ou seja, como totalidade.

Remetendo-nos ao projeto profissional do Serviço Social, hegemônico a partir da década de 1980, a unidade entre teoria e prática se expressa na interação indissociável entre as dimensões teórico-metodológica, ético-política e técnico-operativa. Essa clareza exige a necessidade de trabalhar as três dimensões de forma articulada para que o projeto profissional, que tem como fundamento teórico-metodológico o materialismo histórico e dialético, possa ser, de fato, traduzido em ações concretas. Ou, como afirma Santos $(2010$, p. 5),

[...] teoria e prática mantêm uma relação de unidade na diversidade, formam uma relação intrínseca, sendo o âmbito da primeira o da possibilidade e o da segunda o da efetividade.

As principais alegações sobre a incompatibilidade entre teoria e prática na realidade atual advêm da concepção equivocada que atribui à teoria a capacidade de criar, de imediato, os seus próprios instrumentos, na argumentação de que o materialismo histórico e dialético apresenta a fragilidade de não instrumentalizar a prática profissional. Assim, tornase imprescindível explicitar nossa concepção de teoria e de prática para entender a essência da unidade na diversidade. Afirmamos, ademais, que a base material, concreta, é o solo no qual se fundamentam tanto a teoria quanto a prática.

A teoria é o movimento do pensamento, do ato cognitivo para compreender determinado fenômeno que se expressa na realidade; não pode ser confundida com um receituário a ser aplicado. A partir dessa compreensão, observamos que a teoria não é uma fôrma que se encaixa na prática, tendo em vista que as determinações do concreto são mais dinâmicas do que sua compreensão teórica. Ademais, o objeto real/concreto resulta de múltiplas determinações históricas. $\mathrm{O}$ concreto, que se mostra primeiramente na sua aparência, é construído pelas práticas sociais dos sujeitos históricos e se apresenta como conhecimento na medida em que o pensamento apropria-se desse concreto. A realidade, construída por meio da vida prática, é anterior ao movimento do conhecimento, é o seu ponto de partida e de chegada. Conforme Santos (2010, p. 27),

A teoria se distingue da prática, é ato do pensamento, o qual, todavia, dirige-se para um objeto - produto da prática -, ou seja, a teoria almeja o conhecimento da constituição do concreto, entretanto, esse concreto tem sua gênese na prática, é nela que se expressam as 
determinações do objeto. Dessa forma, teoria e prática se distinguem ao mesmo tempo em que estabelecem uma relação de unidade.

Nesse sentido, teoria e prática possuem movimentos específicos, mas formam uma unidade na diversidade. No caso específico de uma profissão - Serviço Social - que tem uma teoria como fundamento, mas cujas ações expressam-se na prática, ou seja, na intervenção, faz-se necessária uma extrema clareza desses dois movimentos.

Como expressa Iamamoto (2005, p. 73), ao tratar da função social que a profissão Serviço Social assume no processo de reprodução das relações no seio da sociedade capitalista,

É preciso considerar a profissão sob dois ângulos, não dissociáveis entre si, como duas expressões do mesmo fenômeno: como realidade vivida e representada na e pela consciência de seus agentes profissionais expressa pelo discurso teórico-ideológico sobre o exercício profissional; a atuação profissional como atividade social determinada pelas circunstâncias sociais objetivas que conferem uma direção social à prática profissional, o que condiciona e mesmo ultrapassa a vontade e/ou consciência de seus agentes.

O Serviço Social, como profissão socialmente determinada e por isso justificada por uma necessidade gerada pelo conjunto das relações sociais, também possui, na sua própria constituição e maturidade, um projeto profissional construído pelos assistentes sociais, mas em consonância com o contexto histórico vivido. O projeto ético-político profissional do Serviço Social, construído a partir da década de 1980 no Brasil, expressa uma clara articulação com um cenário em que a sociedade brasileira tinha como pauta principal a radicalização da democracia, fortalecida pelas lutas dos trabalhadores num amplo processo de mobilização e construção da consciência de classe.

Nesse contexto, o Serviço Social incorpora, com base na teoria social crítica, o conhecimento acerca dos projetos de classe existentes no país, situando o assistente social na condição de trabalhador assalariado, o que resulta na construção de um projeto profissional em estreita vinculação com as demandas dos trabalhadores.

A compreensão do lugar que a profissão ocupa no conjunto das relações sociais capitalistas e da sua inserção socioinstitucional, mediada por uma autonomia relativa, permitiu a adoção da teoria crítica como referencial para explicação da sociedade e do exercício profissional. A teoria crítica arregimentou a base da construção do projeto ético-político profissional que visa orientar a formação e o exercício profissional ${ }^{3}$. Porém, de acordo com Santos (2010), é muito comum entre a categoria dos assistentes sociais a afirmação de que o materialismo históricoe dialético não instrumentaliza a prática profissional ou, de forma mais corriqueira, que na "prática a teoria é outra".

Marx (2011, p. 25) afirma que "os homens fazem a sua própria história; contudo, não a fazem de livre e espontânea vontade, pois, não são eles quem escolhem as circunstâncias sob as quais ela é feita, mas estas lhes foram transmitidas assim como se encontram". Entre a teoria - possibilidade que se encontra em nível de conhecimento da realidade - e a prática construção efetiva do real a partir das condições históricas estabelecidas - existe um campo de mediações que condiciona limites tanto a uma quanto a outra. Logo, a teoria não é um receituário de indicações a ser aplicado na prática.

A análise do Serviço Social, conectada à história, permite-nos afirmar que hoje vivenciamos um contexto bastante diferenciado daquele da década de 1980. Apontamos como principais alterações: a flexibilização e a precarização exacerbadas do trabalho com impactos para a organização de classe; o Estado destinando parte significativa do fundo público para atender as demandas do grande capital, em especial, do capital financeiro; o desmonte dos direitos sociais com a crescente mercantilização dos serviços sociais que, entre outras situações, afetam negativamente, tanto na dimensão objetiva quanto subjetiva, as condições de vida dos trabalhadores. Tudo isso, fortalecido pela cultura política do individualismo, impõe novos desafios ao Serviço Social e, portanto, exige que a profissão tenha um incisivo rigor teórico-crítico para compreender esse contexto, as possibilidades e os limites de sua intervenção. Assim, o equívoco de considerar que, por estarmos inseridos em um contex to extremamente adverso, ficaríamos impossibilitados de conhecer criticamente a realidade e de apontar alternativas de intervenção, equiparando isso a uma desconexão entre teoria e prática, pode gerar uma série de implicações para a materialidade do projeto profissional. Para o enfrentamento das adversidades que tensionam a concretização da atuação profissional no horizonte da emancipação humana, é preciso que tenhamos muita clareza do lugar que ocupamos como profissionais e dos limites postos a essa condição e, portanto, da necessidade constante de atualização teórica, capacitação técnica e compromisso ético para enfrentá-los.

O Serviço Social, tanto no âmbito da formação quanto do exercício profissional, é constituído pelas dimensões teórico-metodológica, ético-política e técnico-operativa, que formam um todo articulado e indissociável. A articulação entre essas dimensões é apontada, inclusive, como um dos princípios do estágio supervisionado em Serviço Social, na perspectiva de superar equívocos que obscureçam ou autonomizem qualquer um desses as- 
pectos arraigados no movimento de concretude da profissão. Esclarecemos que essas dimensões só podem se efetivar como partes de um mesmo movimento e que nenhuma delas é específica do exercício ou da formação profissional ${ }^{4}$.

Pensar a articulação entre teoria e prática no Serviço Social permite-nos elucidar que a concepção teórico-metodológica exerce influência tanto na definição da finalidade a ser alcançada quanto nos meios a serem utilizados para atingir determinados fins. A escolha da finalidade e dos meios também está vinculada à dimensão ético-política, uma vez que os valores "incidem sobre os conhecimentos necessários à escolha dentre as alternativas possíveis à finalidade em causalidade posta" (SANTOS, 2010, p. 60). Essa vinculação orgânica entre as três dimensões indica que o momento da prática não ocorre desvinculado dos aspectos teórico-metodológicos e ético-políticos. Desse modo, os recursos técnicooperativos adotados na intervenção profissional não estão dissociados das demais dimensões.

Essa compreensão nos impulsiona a afirmar, também, que nenhum instrumento utilizado na prática profissional resulta especifica e imediatamente de alguma determinada teoria. Dito de outra forma, uma teoria não cria seus próprios instrumentos a serem utilizados na prática; é o movimento do real, aliado às possibilidades que ora se apresentam, que inflexionam a utilizá-los. A instrumentalidade ${ }^{5}$ vem sendo, assim, construída na medida em que a profissão consegue materializar suas ações em resposta às demandas que se apresentam no âmbito institucional, ainda que não estejam, de fato, desvinculadas do movimento das relações sociais em sua totalidade.

A falta de interação entre as dimensões da formação e do exercício profissional coloca-se como uma problemática, em especial, para as disciplinas de estágio supervisionado ${ }^{6}$. Por ser uma disciplina teórico-prática, o estágio corporifica a expectativa de que a sua operacionalização possibilite apreender a relação existente entre teoria e prática. No entanto, podemos constatar que, frequentemente, a falta de clareza sobre o que significam essas duas dimensões expressa-se pela expectativa de que o estágio ensine como aplicar a teoria na realidade prática.

Porém, não cabe ao estágio o ensino da prática, nem tampouco o exercício da supervisão acadêmi- ca ou de campo poderia submeter sob sua responsabilidade essa tarefa. Cumpre-nos, enquanto docentes e supervisoras, esclarecer o real sentido da teoria e da prática e a necessidade de sua interlocução. Como afirma Lima (2004), o estágio não é a "hora da prática", mas um espaço de unidade, por possibilitar uma prática fundamentada numa teoria em confronto com a realidade, numa relação dialética que as inter-relaciona, recriando-as no cotidiano. Nesse sentido, é imprescindível que potencializemos o processo de análise crítica da realidade, para que os discentes possam visualizar as reais possibilidades de atuação profissional.

Por isso, afirmamos que o processo de supervisão do estágio em Serviço Social se constrói por meio do acompanhamento, da orientação e reflexão sobre o processo de ensino/aprendizagem, buscando contribuir para a compreensão da unidade teoria/prática e possibilitando o desenvolvimento das competências e habilidades necessárias ao exercício profissional. Cabe à supervisão, como instrumento pedagógico, que orienta e acompanha o estudante durante todo percurso no campo de estágio, capacitá-lo para exercitar e qualificar a prática interventiva, possibilitando a elaboração da síntese do processo de ensino-aprendizagem, a formação de uma postura investigativa e de um posicionamento crítico e propositivo frente à realidade social.

Portanto, a assertiva equivocada de que "a teoria deve ser aplicada à prática" lança o desafio para a formação profissional na medida em que se encontra presente na historiografia do Serviço Social sob três concepções diferenciadas.

A primeira concepção considera que o conhecimento da realidade e o teórico por si só garantem uma boa intervenção profissional, não sendo, portanto, necessária nenhuma disciplina específica. A segunda, está ancorada numa visão tecnicista a partir da qual a prática é fundadora da teoria e, sendo assim, é imprescindível e suficiente uma boa aplicação dos instrumentos e técnicas. A terceira concepção reconhece que a teoria não é aplicada de imediato na prática, fazendo-se importante um acúmulo de conhecimento para o exercício profissional competente (SANTOS, 2010).

Embora o projeto profissional, hoje hegemônico ${ }^{7}$, reafirme a terceira concepção como direção ética e política, a formação e o exercício profissional ainda 
convivem com as três perspectivas apontadas. No momento do estágio, o conflito entre as concepções divergentes sobre a relação entre a teoria e a prática se apresenta de forma mais explícita, pois ao inserirse no espaço socioinstitucional, o discente passa a conviver cotidianamente com os dilemas próprios da intervenção. Em muitos casos, os conflitos ainda são expressos por práticas profissionais com forte viés conservador que se confrontam com o projeto éticopolítico do Serviço Social.

Em meio a esse cenário, a supervisão acadêmica tem o papel fundamental de trazer essas reflexões para o centro da formação profissional ${ }^{8}$, procurando desmistificar as controvérsias que envolvem as concepções sobre teoria e prática, bem como potencializar a perspectiva investigativa indispensável ao exercício profissional.

\section{A supervisão de estágio em Serviço Social: contribuições e desafios da unidade teoria- prática}

A supervisão de estágio em Serviço Social materializa-se por meio do planejamento, orientação, acompanhamento e avaliação do processo de ensino-aprendizagem vivenciado pelos estudantes no estágio supervisionado. Trata-se de uma atribuição privativa dos profissionais de Serviço Social que se efetiva, necessariamente, de forma coletiva, visto que tanto a supervisão acadêmica quanto a de campo, inexistem isoladamente ${ }^{9}$. Nessa perspectiva, a PNE da Associação Brasileira de Ensino e Pesquisa em Serviço Social (ABEPSS, 2010, p. 13) ressalta que

[...] o estágio, enquanto atividade didático-pedagógica, pressupõe a supervisão acadêmica e de campo, numa ação conjunta, integrando planejamento, acompanhamento e avaliação do processo de ensino-aprendizagem e do desempenho do(a) estudante, na perspectiva de desenvolvimento de sua capacidade de investigar, apreender criticamente, estabelecer proposições e intervir na realidade social.

Esta articulação entre supervisão acadêmica e de campo constitui-se um dos princípios da formação profissional em Serviço Social previsto nas Diretrizes Curriculares e incorporado na definição de supervisão direta contida na Resolução n. 533/2008 do Conselho Federal de Serviço Social, que regulamenta a supervisão de estagiários:

A conjugação entre a atividade de aprendizado desenvolvida pelo aluno no campo de estágio, sob o acompanhamento direto do supervisor de campo e a orientação e avaliação a serem efetivadas pelo supervisor vinculado a instituição de ensino, resulta na supervisão direta (CFESS, 2008, Art. 4, § 1).

Destarte, a supervisão direta se efetiva, de forma articulada, no âmbito da formação e do exercício profissional, o que potencializa a compreensão da realidade e a construção de propostas de intervenção alicerçadas na identificação e discussão das inúmeras possibilidades e dos desafios que perpassam a profissão, o que não prescinde a reflexão sobre a unidade entre teoria e prática.

Assim, a especificidade do estágio como disciplina de caráter teórico-prático, que ocorre tanto nas unidades de formação acadêmica quanto nos espaços de inserção sócio-ocupacional do assistente social, e cujos conteúdos se articulam com os componentes da formação profissional, viabiliza a interlocução entre essas instâncias e os sujeitos envolvidos no processo. Dessa forma, o estágio é operacionalizado mediante a supervisão acadêmica e de campo, com a participação de assistentes sociais que atuam na docência universitária e de assistentes sociais inseridos nos mais diversos campos de atuação profissional. Por essas particularidades, o estágio também se expressa como o momento em que se torna mais visível a problemática entre teoria e prática, ou melhor, a relação que se estabelece e/ou que é percebida entre estas no cotidiano da operacionalização do trabalho dos assistentes sociais.

Convém destacar que

\begin{abstract}
A supervisão não pode ser compreendida desvinculada dos seus componentes teórico, ético e político, da compreensão do significado social do Serviço Social na sociedade brasileira, dos valores que privilegia, de um projeto profissional que se conecta (ainda que por meio de muitas mediações) a projetos de sociedade (BRAGA; GUERRA, 2009, p. 534).
\end{abstract}

Isto impõe como desafio para a supervisão o aprofundamento teórico que possibilite aos sujeitos desvelar a realidade para além da superficialidade dos fenômenos, o que só é possível na sua articulação com a totalidade social. A nosso ver, este esforço de análise é fundamental para possibilitar a construção de ações capazes de transpor o pragmatismo e a imediaticidade, presentes na cotidianidade dos serviços socioinstitucionais, âmbito do trabalho profissional.

Para Braga e Guerra (2009, p. 533), a supervisão é entendida como:

[...] uma atribuição profissional que se localiza no âmbito da formação graduada e permanente para a qualificação dos serviços prestados à sociedade, 
direcionada para a realização dos objetivos, valores, princípios e direção social estratégica do projeto ético-político profissional com vistas à emancipação social.

Apesar da imprescindível articulação entre a supervisão acadêmica e a de campo, essas atividades possuem particularidades que as distinguem e se configuram como

[...] duas dimensões distintas, mas não excludentes de acompanhamento e orientação profissional: uma supervisão acadêmica que caracteriza a prática docente e, portanto, sob responsabilidade do(a) professor(a)-supervisor(a) no contexto do curso e a supervisão de campo, que compreende o acompanhamento direto das atividades práticoinstitucionais da(o) estudante pelo(a) assistente social, nos campos de estágio. Estas dimensões devem estar diretamente articuladas em todo processo de supervisão (ABEPSS, 2010, p. 19).

Há, portanto, diferenças e particularidades no desempenho da supervisão acadêmica e de campo, o que não significa a existência de uma dicotomia entre elas, embora haja profundos desafios para a concretização de uma relação mais intensa entre os supervisores. É importante esclarecer, contudo, que muitos destes desafios perduram mesmo diante do compromisso e da competência dos profissionais, visto que advêm da precarização das condições e relações de trabalho impostas aos trabalhadores, dentre estes os assistentes sociais. Resulta em intensa e extensa jornada de trabalho, reduzindo o tempo de dedicação à supervisão de estágio.

No que se refere às dificuldades no entendimento dos papéis assumidos pelos supervisores acadêmicos e de campo, recente pesquisa ${ }^{10}$ vinculada ao Programa Institucional de Bolsas de Iniciação Científica (Pibic), realizada no âmbito da Faculdade de Serviço Social da UERN, evidenciou que existe uma dificuldade em definir supervisão, apesar de sua importância para os estagiários e para as próprias supervisoras. A pesquisa aponta ainda uma fragilidade sobre a compreensão das atribuições das supervisoras, verificando-se uma tendência a mencionar a supervisão de campo como uma atividade do ensino da prática ou do manejo de instrumentos e técnicas próprias do exercício profissional. Por outro lado, a supervisão acadêmica é concebida, por parte de algumas supervisoras de campo, como atividade vinculada somente às orientações teóricas (ROSADO; SILVA, 2011).

Analisando essa diferenciação elaborada por algumas das supervisoras, verificamos que, embora existam particularidades inerentes a cada uma dessas modalidades de supervisão, a incompreensão dessas particularidades pode desencadear uma equivo- cada interpretação de que haveria a dissociação entre teoria e prática. Por isso, a importância de fortalecer a supervisão conjunta na qual teoria e prática possam ser discutidas de forma articulada. Destacamos, também, que a dimensão ético-política da supervisão de estágio, em indissociável articulação com os aspectos teórico-metodológicos e técnicooperativos, deve ser reconhecida como parte integrante da formação profissional em sua totalidade. Nessa perspectiva, o estudo e a reflexão acerca da dimensão ético-política deve ser incorporado como parte das responsabilidades de ambos os supervisores, visando a construção e o fortalecimento do compromisso dos estagiários com o projeto éticopolítico do Serviço Social.

Dessa forma, o fortalecimento das potencialidades da supervisão requer a intensificação da articulação entre os sujeitos envolvidos. Iniciativa que se configura profundamente desafiadora, particularmente nesta conjuntura marcada pelo atual processo de reestruturação do capital, cujos desdobramentos atingem todos os segmentos trabalhadores.

No sentido de fortalecer o momento do Estágio como processo síntese da formação profissional e que tem, portanto, a supervisão como elemento determinante para sua realização, vários esforços vêm sendo efetivados pelas entidades da categoria. Ressaltamos dois grandes avanços nessa direção: a Resolução n. 533/2008, do CFESS e a PNE. Ambas apontam elementos fundamentais para a realização do estágio obrigatório e não obrigatório como processo de articulação entre teoria e prática, que necessita de supervisão direta e no qual se torna indispensável a vinculação entre as dimensões teóricometodológica, ético-política e técnico-operativa.

Podemos perceber que o momento de operacionalização do estágio possibilita que todas as dimensões da formação profissional e todos os conteúdos trabalhados pelas disciplinas coloquem-se em articulação permanente. Esse movimento é impulsionado, em grande parte, pelas supervisões acadêmica e de campo que possuem um potencial mobilizador dos elementos constitutivos da unidade teoria-prática.

Diante do exposto, reconhecemos ser imprescindível a materialização da indissociabilidade entre a supervisão acadêmica e a de campo, bem como o fortalecimento do potencial do estágio supervisionado enquanto espaço propício para a compreensão da unidade teoria-prática. Por outro lado, é possível observar que todas as regulamentações construídas pelas entidades representativas do Serviço Social apontam na direção dessa articulação. A Resolução de Estágio e a PNE contêm avanços que buscam assegurar a direção social da profissão, pautada em valores democráticos e emancipatórios e teoricamente alicerçada na teoria crítica, ao mesmo tempo que garante a qualidade da formação profissional em um 
contexto de extrema investida do capital em precarizar o ensino superior.

A necessária compreensão da unidade entre a teoria e a prática, assim como a imperatividade de sua materialização, não é tarefa exclusiva da supervisão ou do momento de realização do estágio. Somente é possível garantir a efetividade do projeto profissional do Serviço Social na medida em que a dicotomia entre teoria e prática seja superada por uma intervenção que busque concretizar a investigação, a reflexão e a ação numa constante e indissociável articulação. Esse movimento deve perpassar todo o processo de formação profissional na perspectiva de garantir um perfil de assistentes sociais comprometidos com a análise crítica, que façam da sua prática não o simples manuseio dos instrumentos e técnicas, mas uma atuação pautada nessa análise, sem negligenciar as condicionalidades postas pelo espaço socioinstitucional.

\section{Reflexões conclusivas: avanços e desafios do estágio e da supervisão}

Consoante com as indicações da Resolução n. 533 e da PNE, instrumentos que orientam a supervisão e o estágio na perspectiva da consolidação do projeto ético-político do Serviço Social, a Faculdade de Serviço Social da UERN vem implementando ações para fortalecer a materialização desses instrumentos e potencializar o momento do estágio.

Nessa perspectiva, pontuamos alguns dos avanços já conquistados na nossa unidade de ensino, bem como sinalizamos os desafios a serem ainda enfrentados.

Evidenciamos os avanços em dois eixos: um refere-se especificamente ao processo de organização do estágio obrigatório e da supervisão direta; o outro focaliza o estágio não obrigatório, possível de se constituir em um dos elementos complementares da formação profissional.

No que se refere à organização do estágio obrigatório e à supervisão, destacamos as visitas periódicas da supervisão acadêmica aos campos de estágio. Essas visitas objetivam diminuir a distância entre a academia e os campos de atuação e fomentar discussões que ampliem a compreensão da indissociabilidade entre teoria e prática. Essas atividades são demandas explicitadas no Fórum de Supervisoras e nos Seminários de Socialização das Experiências de Estágio ${ }^{11}$, sendo vislumbradas como imprescindíveis para manter a articulação entre os profissionais, as instituições e a própria realização do estágio.

Durante as visitas, observamos que as reflexões postas por assistentes sociais e estudantes possibilitam entender e desvelar os equívocos resultantes da dicotomia entre teoria e prática. Este é um momento extremamente importante para potencializar essa compreensão e, acima de tudo, romper com a ideia de que a teoria é própria da academia e a prática pertence aos assistentes sociais que não estão na docência ${ }^{12}$.

Acreditamos que seja preciso investir mais na aproximação da Universidade com os campos de estágio. Essa é uma interação que depende da carga horária docente para atividades de campo e da realidade da dinâmica de funcionamento dos campos. Para favorecer esta interação, nossas turmas de estágio são formadas com, no máximo, três estudantes, cabendo a cada docente, entre as turmas que assume, de quatro a nove estagiários. Dessa forma, no âmbito do curso de Serviço Social da UERN, vem sendo atendida a indicação da PNE quanto ao máximo de 15 estudantes por turma.

Outro avanço importante, também indicado na PNE, foi a inclusão, para os ingressantes no curso a partir de 2010, na disciplina Estágio Supervisionado em Serviço Social, da autoavaliação, expressa em uma nota de zero a dez, que passa a compor a média final, juntamente com as notas atribuídas pelos supervisores acadêmicos e de campo, possuindo todas o mesmo peso.

Entre as iniciativas que têm fortalecido o desenvolvimento do estágio, destacam-se a atuação da Comissão de Estágio ${ }^{13}$ e a do Fórum de Supervisoras de Estágio que se configura como espaço aberto à participação de todos os supervisores acadêmicos e de campo. Essas duas instâncias têm exercido um papel importante para discussões coletivas acerca dos problemas e entraves relacionados ao estágio, e para propiciar a realização de palestras e estudos, incluindo-se a relação teoria-prática. No Fórum de Supervisores de Estágio, discutimos e elaboramos as propostas sobre: instrumentos de avaliação; indicações para nortear a elaboração do projeto de trabalho e do plano de estágio ${ }^{14}$; e instrumento para acompanhamento e registro das horas de estágio.

A organização dessas instâncias, e do estágio em sua totalidade, é feita pela Coordenação de Estágio ${ }^{15}$ como esfera de gestão dessa política. A coordenação assume a função de articular os diversos sujeitos envolvidos no estágio, de observar em conjunto com esses sujeitos as condições éticas e técnicas para a realização do estágio, de manter a articulação com o Conselho Regional de Serviço Social, com todas as instituições campo de estágio e com o setor de estágio da Universidade.

Quanto ao estágio não obrigatório, ainda vivenciamos dificuldades no acompanhamento deste processo educacional, visto que os períodos de início e suspensão desta atividade nem sempre coincidem com o semestre letivo. Há dificuldades no reconhecimento da vinculação desta modalidade de estágio ao processo de formação profissional e, portanto, persistem fragilidades em sua relação com a supervisão acadêmica e de campo. Entretanto, desde 2010, o Projeto Pedagógico do curso, bem como a resolu- 
ção que normatiza a distribuição de carga horária docente na UERN, prevê a garantia de carga horária para a supervisão do estágio curricular não obrigatório, sendo duas horas semanais para cada instituição, independentemente do número de estagiários. Apesar da realização de encontros e reuniões para o fortalecimento desse tipo de estágio, ainda vislumbramos um grande percurso a ser trilhado, especialmente no que tange ao estabelecimento das condições fundamentais exigidas para este processo didático-pedagógico. Como podemos constatar, em meio aos avanços citados, convivemos com diversos desafios, entre eles o enfrentamento da precarização das condições de trabalho, principalmente no que se refere às extensas e intensas jornadas de trabalho dos supervisores.

Por fim, reafirmamos que a articulação entre as dimensões teórico-metodológica, ético-política e técnico-operativa, assim como a concepção da indissociabilidade entre teoria e prática, fundamental para materialização do projeto ético-político do Serviço Social, deve perpassar toda a formação e todo o exercício profissional, não sendo exclusiva de nenhuma disciplina. Compreendemos, porém, que o momento do estágio, como disciplina que se operacionaliza na academia e nos demais campos de atuação apresenta-se como síntese desse processo acadêmico, pois potencializa a vivência dos estudantes na realidade concreta da intervenção.

\section{Referências}

ABEPSS. Política Nacional de Estágio. Brasília, 2010. Disponível em: 〈www.abepss.org.br〉. Acesso em: 6 mar. 2012.

BRAGA, M. E.; GUERRA, Y. Supervisão em Serviço Social. In: CFESS; ABEPSS. Serviço Social: direitos sociais e competências profissionais. Brasília: Cfess/Abepss, 2009.

BRASIL. Presidência da República. Lei n. 8.662 de 1993. Disponível em: <http://www.planalto.gov.br/ccivil 03/leis/ L8662.htm>. Acesso em: 17 dez. 2011.

BRAZ, M. A hegemonia em xeque. Projeto ético-político do Serviço Social e seus elementos constitutivos. Revista Inscrita, n. 10, p. 4-10, 2007.

CFESS. Código de Ética do Assistente Social. 1993. Disponível em: 〈http://www.cfess.org.br/arquivos/CEP 1993.pdf>. Acesso em: 10 mar. 2012.

. Resolução $n$. 533. Regulamenta a supervisão direta de estágio no Serviço Social. Brasília, 29 de setembro de 2008.

CISNE, M. Resistência de classe no Brasil contemporâneo: mediações políticas para o enraizamento do Projeto Ético-
Político do Serviço Social. Temporalis, n. 16, p. 67-96, 2008.

GUERRA, Y. A instrumentalidade do Serviço Social. São Paulo: Cortez, 1995.

IAMAMOTO, M. V. Relações sociais e Serviço Social no Brasil: esboço de uma interpretação histórico-metodológica. São Paulo: Cortez, 2005.

Serviço Social em tempo de capital fetiche: capital financeiro, trabalho e questão social. São Paulo: Cortez, 2008.

LIMA, M. S. L. A hora da prática: reflexões sobre o estágio supervisionado e a ação docente. Fortaleza: Demócrito Rocha, 2004.

MARX, K. O 18 de Brumário de Luís Bonaparte. Tradução de Nélio Schneider. São Paulo: Boitempo, 2011.

RAMOS, S. R. A mediação das organizações políticas. Revista Inscrita, n. 10, p. 41-46, 2007.

ROSADO, I. V. M.; SILVA, K. L. da. Potencialidades e desafios da supervisão de estágio: uma análise a partir da realidade vivenciada pelas(os) assistentes sociais dos campos de estágio da Fasso/UERN. Mossoró, 2011. (Relatório de Pesquisa).

SANTOS, C. M. dos. Na prática a teoria é outra? Mitos e dilemas na relação entre teoria, prática, instrumentos e técnicas no Serviço Social. Rio de Janeiro: Lumen Juris, 2010.

UERN-Universidade do Estado do Rio Grande do Norte. Projeto Político Pedagógico do Curso de Serviço Social. Mossoró, 2009.

\section{Notas}

1 Com exceção dos casos em que o gênero já vem definido pelo conteúdo, optamos por utilizar, apenas por uma questão de simplificação da redação, as formas de gêneros predominantes, conforme a gramática. Nesses casos, destacamos que estamos sempre nos referindo tanto ao gênero feminino quanto ao masculino.

2 De acordo com o Projeto Político Pedagógico do Curso de Serviço Social da UERN, considera-se turma de estágio um grupo de estudantes, composto por no mínimo dois e no máximo quatro estagiários, inseridos no mesmo setor de um determinado campo de estágio e acompanhados por um único supervisor de campo. De acordo com a Resolução n. 533/2008 do Conselho Federal de Serviço Social (CFESS, 2008), a quantidade de estagiários a serem supervisionados pelos supervisores de campo não deve ultrapassar o número de um estudante para cada 10 horas semanais de trabalho. Com a conquista das 30 horas de trabalho semanal para os assistentes sociais, cada supervisora de campo poderá supervisionar no máximo três estagiários. A 
supervisão por área de intervenção reúne todos os estudantes e supervisores acadêmicos e de campo de determinada área.

3 Para uma análise mais detalhada, ver Iamamoto (2008).

4 Háa preocupação em enfatizar a unidade entre as dimensões teóricometodológica, ético-política e técnico-operativa e em salientar que a importância de tratar os instrumentos e técnicas "para além de sua operacionalidade" não está sendo apreendida como "um descuido com a operacionalizaçãoe suas especificidades no Serviço Social". Discutir tais instrumentos e técnicas envolve o "o que fazer", o "para que fazer", "o por que fazer", mas, também, o "como fazer". O currículo não pode prescindir de disciplinas que tratem da habilitação para o manuseio dos instrumentos e técnicas no Serviço Social em conjugação com o debate filosófico, teórico, político e ético (SANTOS, 2010, p. 8).

5 VerGuerra (1995).

6 NoProjeto Pedagógico do Curso de Serviço Social da UERN (2009), fundamentado nas Diretrizes Curriculares e nos demais instrumentos construídos no âmbito das entidades organizativas da profissão, o estágio supervisionado é definido como atividade curricular que se configura por meio da inserção do estudante no espaço socioinstitucional, objetivando capacitá-lo para o exercício profissional, o que pressupõe supervisão sistemática. Esta supervisão será feita pelo professor supervisor e pelo profissional de Serviço Social do campo de estágio, com base em planos de estágio, tendo como referência a Lei n. 8.662/93 (BRASIL, 1993), o Código de Ética do Profissional (CFESS, 1993) e a Resoluçãon. 533 (CFESS, 2008).

7 De acordo com Braz (2007, p. 6), três fatores são determinantes para manutenção da hegemonia do projeto-ético político do Serviço Social: "a) uma dimensão teórica, que envolve o conjunto da produção de conhecimentos no Serviço Social; b) uma dimensão jurídicopolítica, identificada no âmbito dos construtos legais da profissão (tanto as leis estritamente profissionais, quanto a legislação social mais ampla; c) e uma dimensão político-organizativa, ancorada nos fóruns coletivos das entidades representativas do Serviço Social". Partindo dessa afirmação, concordamos com Ramos (2007) e Cisne (2008) ao avaliarem que esses três pilares ainda sustentam o projeto ético-político arquitetado na década de 1980, o que o torna hegemônico.

8 Essa tarefa não é exclusiva da supervisão acadêmica, apenas destacamos como particularidade por evidenciar o processo da formação profissional.

9 A indissociabilidade entre a supervisão acadêmica e a de campo está prevista na Lei de Regulamentação da Profissão (Lei n. 8662/93), no Código de Ética do Assistente Social, na Resolução CFESS N. 533/2008, que regulamenta a supervisão de estagiários de Serviço Social e na Política Nacional de Estágio.

10 Pesquisa realizada em 2009 e 2010, com 32 assistentes sociais, apontou, além das condiçõeséticase técnicas para o desenvolvimento do trabalho, a concepção que esses sujeitos têm acerca da supervisão e do próprio estágio. Neste artigo, detemo-nos nas questões concernentes à concepção de supervisão e sua vinculação com a relação entre teoria e prática.

11 Os Seminários de Socialização das Experiências de Estágio vêm sendo promovidos anualmente pela Faculdade de Serviço Social da UERN, desde 2004, com a participação de estudantes, supervisores acadêmicos e de campo, além de assistentes sociais.

12 Existe ainda uma polêmica de que os assistentes sociais que trabalham na docência universitária não estariam assumindo funções próprias da profissão. Essa é uma visão equivocada que não nos cabe aqui analisar apenas a sinalizamos por gerar outros equívocos, em especial, no que diz respeito à relação entre teoria e prática.

13 A comissão de estágio supervisionadoé um espaço de discussões e encaminhamentos das questões referentes ao estágio e deve ser composta por três professores (assistentes sociais) do Departamento de Serviço Social (Desso). Dentre esses, um coordenador de estágio; dois representantes dos supervisores de campo e dois representantes dos estudantes (UERN, 2009).

14 Instrumentos obrigatórios a partir da aprovação da Resolução n. 533 (CFESS, 2008).

15 A coordenação de estágioé o órgão administrativo da Faculdade de Serviço Social (Fasso) que tem por objetivo a organização, a administração e o planejamento do processo de estágio como parte da formação profissional, fazendo a articulação Fasso/Desso com os campos de estágio.

\section{Rivânia Lúcia Moura de Assis}

rivanialma@hotmail.com

Doutoranda do Programa de Pós-Graduação em Serviço Social da Universidade Federal do Rio de Janeiro (PPGSS/UFRJ)

Professora na Faculdade de Serviço Social da Universidade do Estado do Rio Grande do Norte (UERN)

\section{Iana Vasconcelos Moreira Rosado}

ianavasconcelos@uern.br

Doutoranda do Programa de Pós-Graduação em Ciências da Saúde da Universidade Federal do Rio Grande do Norte (UFRN)

Professora na Faculdade de Serviço Social da UERN

\section{UERN - Faculdade de Serviço Social}

Campus Universitário Central, Setor I

Rua Professor Antônio Campos, s/n

Mossoró - Rio Grande do Norte

CEP: 59610-090 